\title{
Safety of transanal ileal pouch-anal anastomosis for ulcerative colitis: a retrospective observational cohort study
}

\author{
Aina Lask ${ }^{* *}$ (D, Matthias Biebl ${ }^{1}$, Luca Dittrich ${ }^{1}$, Andreas Fischer ${ }^{2}$, Andreas Adler², Frank Tacke ${ }^{2}$, Felix Aigner ${ }^{3}$, \\ Rosa Schmuck', Sascha Chopra', Michael Knoop', Johann Pratschke ${ }^{1}$ and Safak Gül-Klein ${ }^{1 *}$
}

\begin{abstract}
Background: Colectomy with transanal ileal pouch-anal anastomosis (talPAA) is a surgical technique that can be used to treat benign colorectal disease. Ulcerative colitis is the most frequent inflammatory bowel disease (IBD) and although pharmacological therapy has improved, colectomy rates reach up to $15 \%$. The objective of this study was to determine anastomotic leakage rates and treatment after talPAA as well as short- and long-term pouch function.

Methods: We conducted a retrospective analysis of a prospective database of all patients undergoing talPAA at an academic tertiary referral center in Germany, between 01/03/2015 and 31/08/2019. Patients with indications other than ulcerative colitis or with adjuvant chemotherapy following colectomy for colorectal carcinoma were excluded for short- and long-term follow up due to diverging postoperative care yet considered for evaluation of anastomotic leakage.

Results: A total of 22 patients undergoing talPAA during the study time-window were included in analysis. Median age at the time of surgery was $32 \pm 12.5(14-54)$ years. Two patients developed an anastomotic leakage at 11 days (early anastomotic leakage) and 9 months (late anastomotic leakage) after surgery, respectively. In both patients, pouches could be preserved with a multimodal approach. Twenty patients out of 22 met the inclusion criteria for short and long term follow-up. Data on short-term pouch function could be obtained in 14 patients and showed satisfactory pouch function with only four patients reporting intermittent incontinence at a median stool frequency of 9-10 times per day. In the long-term we observed an inflammation or "pouchitis" in 11 patients and a pouch failure in one patient.

Conclusion: Postoperative complication rates in patients with benign colorectal disease remain an area of concern for surgical patient safety. In this pilot study on 22 selected patients, talPAA was associated with two patients developing anastomotic leakage. Future large-scale validation studies are required to determine the safety and feasibility of talPAA in patients with ulcerative colitis.
\end{abstract}

Keywords: Transanal ileal pouch-anal anastomosis, Pouchitis, Ulcerative colitis, Anastomotic leakage

\footnotetext{
*Correspondence: aina.lask@charite.de; safak.guel@charite.de

1 Department of Surgery, Campus Charité Mitte and Campus Virchow-

Klinikum, Charité - Universitätsmedizin Berlin, Augustenburger Platz 1,

13353 Berlin, Germany

Full list of author information is available at the end of the article
} permits use, sharing, adaptation, distribution and reproduction in any medium or format, as long as you give appropriate credit to the original author(s) and the source, provide a link to the Creative Commons licence, and indicate if changes were made. The images or other third party material in this article are included in the article's Creative Commons licence, unless indicated otherwise in a credit line to the material. If material is not included in the article's Creative Commons licence and your intended use is not permitted by statutory regulation or exceeds the permitted use, you will need to obtain permission directly from the copyright holder. To view a copy of this licence, visit http://creativecommons.org/licenses/by/4.0/. The Creative Commons Public Domain Dedication waiver (http://creativeco mmons.org/publicdomain/zero/1.0/) applies to the data made available in this article, unless otherwise stated in a credit line to the data. 


\section{Background}

Ulcerative colitis is the most common inflammatory bowel disease (IBD) and exceeds the incidence and prevalence of Crohn's disease in most countries around the world [1]. Over the past few decades, pharmacologic therapy has improved, limiting the need for surgery to cases of refractory or steroid-dependent disease, colorectal cancer or surgical emergencies such as toxic megacolon, perforation or life-threatening hemorrhages [2]. Throughout the course of the disease, medical therapy refractory ulcerative colitis, which requires surgical treatment, leads to reconstructive surgery rates by restoring continuity of up to $15 \%$ [3]. In this regard, the use of minimally invasive ileal pouch-anal anastomosis (IPAA) is the favored technique $[4,5]$.

Transanal total mesorectal excision was established for sphincter-preserving rectal resection due to rectal carcinoma, providing better access and overview especially in obese patients or male individuals with naturally narrow pelvises [6, 7]. Subsequently, transanal minimally invasive surgery has also been implemented in operations for transanal IPAA (taIPAA) and, as already proven in various studies, also provides satisfactory surgical results and comparable complication rates to the pure transabdominal approach [8-10]. Anastomotic leakage is a common complication in colorectal surgery with significant postoperative morbidity [11]. Irrespective of the presence of benign or malignant disease as a surgical indication, anastomotic leakage results in chronic inflammation, fistulae or stenosis, reduced quality of life and eventually anastomotic failure with permanent stoma [11-13]. Additionally, in colorectal carcinoma, anastomotic leakage is associated with reduced disease-free and overall survival $[14,15]$. Besides anastomotic leakage, pouchitis is the most frequent complication of IPAA significantly impairing pouch function and quality of life $[16,17]$. Anastomotic leakage in association to pouch complications might be of relevant impact for pouch failure after IPAA $[9,18]$.

The multimodal treatment procedures of anastomotic leakage management include-depending on the extent of anastomotic leakage-antibiotic therapy, radiological or endoscopic interventions as well as reoperation with the intend to preserve continuity, as recently shown by different groups for anastomotic leakage for rectal cancer and IBD [19-21].

Therefore, the aim of our retrospective study was to analyze patients after taIPAA due to benign colorectal disease regarding incidence and course of anastomotic leakage as well as episodes of pouchitis and associated hospital readmissions.

\section{Methods}

Study design

All consecutive patients subjected to a taIPAA in our department were analyzed retrospectively. All patients eligible for laparoscopic resection were offered the transanal approach. Those who chose taIPAA were prospectively recruited and gave written informed consent for the international LOREC ${ }^{\circledR}$ registry. The study was performed in accordance with the Declaration of Helsinki and its amendments and an authorization has been granted by the Charité Ethics Committee (Reg. No. 711/16). For clinical data such as sex, date of birth, preoperative data (therapy, body-mass-index (BMI), extent of inflammation), operative data (operation time) and postoperative course as well as shortand long-term follow-up data (complications according to Clavien-Dindo classification; readmissions), patient data were collected anonymously.

In our retrospective single-center observational cohort study we hypothesized, that taIPAA is a safe procedure for restorative proctocolectomy in patients suffering from ulcerative colitis and provides satisfactory short- and long-term outcome.

From $01 / 03 / 2015$ to $31 / 08 / 2019$, taIPAA, performed in the context of a two- or three-staged restorative proctocolectomy, was applied in 22 patients suffering benign colorectal disease at our Department of Surgery, Campus Virchow Klinikum and Campus Charité Mitte at Charité-Universitätsmedizin Berlin. For the analysis of anastomotic leakage, we included all patients who received taIPAA. To evaluate short- and long-term postoperative outcome, we only considered taIPAA in patients with ulcerative colitis and hence excluded two patients. Of those, one suffered from familial adenomatosis polyposis and the other one was diagnosed with ulcerative colitis but excluded due to additional colorectal carcinoma with hyperthermic intraperitoneal chemotherapy prior to pouch formation and adjuvant chemotherapy after colectomy and therefore diverging postoperative care (Table 1 and Fig. 1).

Relevant data (clinical course, laboratory chemical parameters, hospital stay, readmissions) for our patient cohort were analyzed retrospectively. Postoperative complications were defined according to Clavien-Dindo with special emphasis on complications $>$ II.

Occurrence of early (within the first 30 days) and late (31 to 90 days or later) anastomotic leakage was the primary endpoint. Anastomotic leakage is defined as dehiscence of the anastomotic circumference leading to a communication between the intra- and extraluminal compartments. In our study, diagnosis of anastomotic leakage was made when dehiscence of the anastomotic circumference was confirmed via endoscopy. Secondary 
Table 1 Patient characteristics and operative details

\begin{tabular}{|c|c|}
\hline Patients & $n=22$ \\
\hline Sex (male) & 14 \\
\hline Median age (years, $\pm S D$, range) & $32 \pm 12.5(14-72)$ \\
\hline Mean BMI (kg/m²,$\pm \mathrm{SD}$, range) & $22.8 \pm 3.7(17-32.8)$ \\
\hline \multicolumn{2}{|l|}{ ASA Score } \\
\hline 1 & 4 \\
\hline$\|$ & 16 \\
\hline III & 2 \\
\hline \multicolumn{2}{|l|}{ Pre-existing health conditions } \\
\hline Smoker & 0 \\
\hline Diabetes & 2 \\
\hline Previous abdominal operation & 5 \\
\hline $\begin{array}{l}\text { Median time from diagnosis of ulcerative colitis } \\
\text { to operation (months, } \pm \mathrm{SD} \text {, range) }\end{array}$ & $36 \pm 104.5(1-408)$ \\
\hline Three staged procedure & 19 \\
\hline Two staged procedure & 3 \\
\hline $\begin{array}{l}\text { Mean operation time talPAA (minutes, } \pm \text { SD, } \\
\text { range) }\end{array}$ & $362 \pm 163(134-905)$ \\
\hline \multicolumn{2}{|l|}{ Anastomosis } \\
\hline Stapled & 8 \\
\hline Handsewn & 14 \\
\hline $\begin{array}{l}\text { Cufflength ( } \mathrm{cm} \text { from pectinate line, median and } \\
\text { range) }\end{array}$ & $1(0-3)$ \\
\hline
\end{tabular}

$B M I$ Body Mass Index, ASA American society of Anaesthesiologists, talPAA Transanal ileal pouch-anal anastomosis

endpoints included pouch complications (pouchitis, fistula, stenosis). These endpoints were assessed and evaluated at regular follow-ups at our Departments of Surgery or Gastroenterology. One patient did not receive ileostomy closure at our surgical department, hence data on short- and long-term follow up could not be obtained.

\section{Surgical technique}

The whole operation procedure for ulcerative colitis was performed either as a two- or three-staged procedure with an interval of three to six months between procedures. The first operation comprised subtotal colectomy and terminal ileostomy, the second operation included an ileal proctectomy following the prior colectomy and pouch-anal anastomosis with diverting loop-ileostomy.

All patients were operated in a simultaneous transanal and abdominal technique. After excision and closure of terminal ileostomy followed the insertion of a single port and placement of the capnoperitoneum. With an additional $5 \mathrm{~mm}$ trocar in the left mid-abdomen the entire small intestine was mobilized and adhesions were removed up to the duodenum. Through the port, the J-pouch was created starting from the apex of the mesenteric vessel axis. The staple suture on the distal limb was sewn over and the apex of the pouch came to rest loosely below the symphysis. Following the pouch confection, mesorectal mobilization was carried out next. Simultaneously, after rinsing the rectal stump with $\mathrm{NaCl}$-Iodide solution, a tobacco-pouch suture was placed $3 \mathrm{~cm}$ above the pectinate line to close the rectum. Subsequently, the rectum was incised $2 \mathrm{~cm}$ above the pectinate line and the single-incision-laparoscopic-surgery port was inserted and fixed to the perianal skin. Placement of the capnosubperitoneum was followed by the preparation of the mesorectal layer. After successful dissection using the rendez-vous method, the peritoneal cavity was reached and the rectum was retrieved via the port site. Ileal pouch-anal anastomosis was either stapled or handsewn followed by creation of a diverting loop-ileostomy. Perioperative antibiotic prophylaxis using cefuroxime and metronidazol was given to all patients.

The last operation consisted of ileostomy closure. Beforehand, an endoscopy of the pouch was performed to exclude severe inflammation (pouchitis) or anastomotic leakage. No further diagnostic measures (as e.g. CT-scan or rectal contrast application) were taken. Ileostomy closure only took place after constating absence of inflammation and inconspicuous anastomosis region.

In two patients, colectomy as well as pouch confection were performed simultaneously due to one patients excellent inflammation remission and the other patients diagnosis of non-inflammatory familiar adenomatosis polyposis. One patient in our cohort did not undergo loop ileostomy due to severe adhesions. Diverting loop ileostomy is standard at our institution, but may be considered optional in patients at very low risk for anastomotic leakage and/ or increased risk for complications. All operations for pouch confection were conducted in a hybrid technique including minimally invasive transabdominal approach and combined transanal approach.

\section{Data collection}

Data was collected in a prospective database for patients receiving taIPAA and analyzed retrospectively for perioperative complications and postoperative clinical course. Subsequent data were analyzed: demographics (age, gender), body-mass-index (BMI), American society of Anaesthesiologists (ASA) score, comorbidities, preoperative course of disease, operative details (Table 1), postoperative morbidity and mortality, complications with special focus on anastomotic leakage (time of diagnosis, treatment approach, treatment duration) (Table 2), shortterm (first 60 days after ileostomy closure) (Table 3), and long-term ( 1 to 5 years after ileostomy closure) pouch function (Table 4), pouchitis (clinical symptoms, 


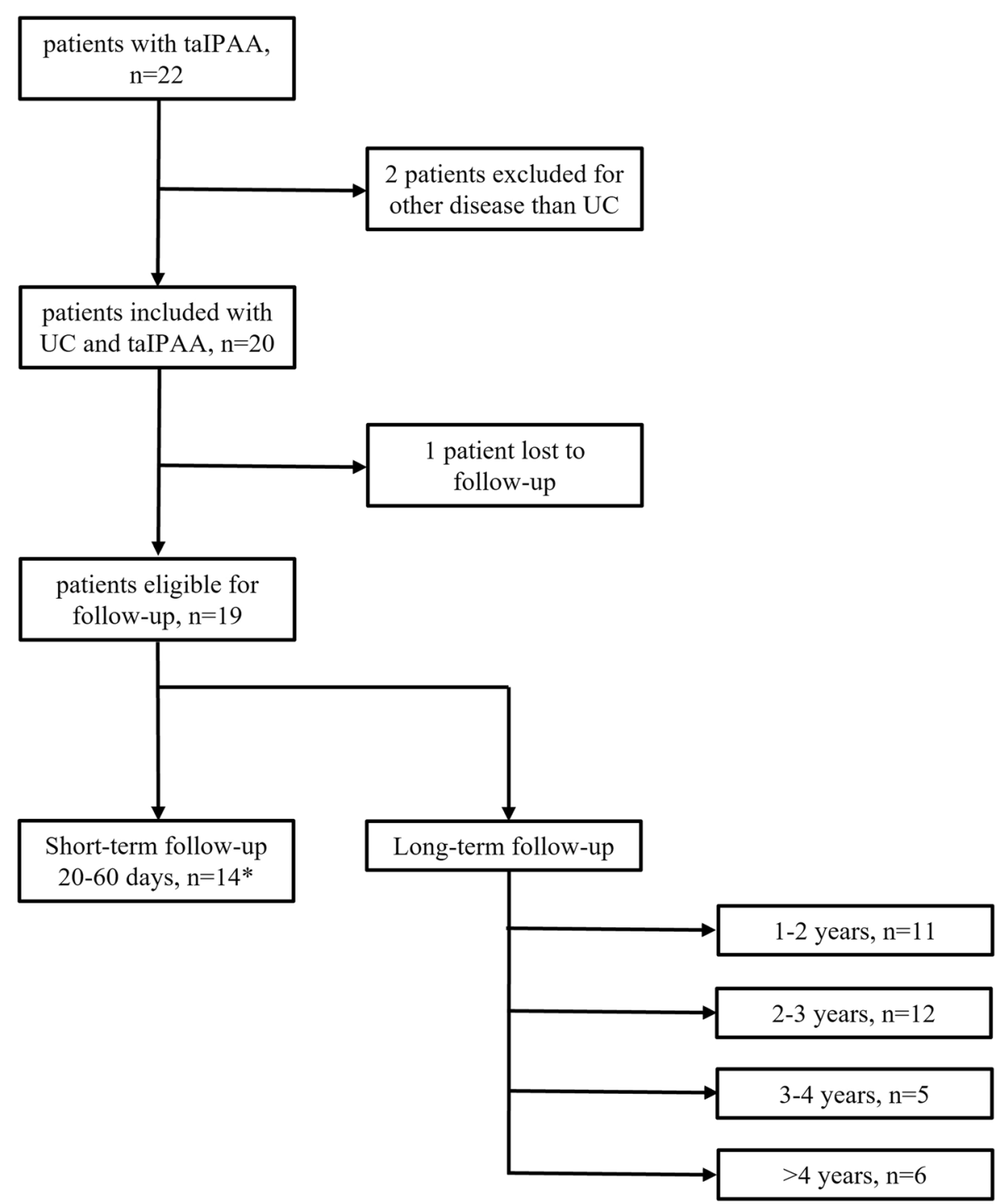

Fig. 1 Patient cohort, * Five patients rejected routine postoperative follow up at our department of surgery within 20 to 60 days due to good clinical status in ambulatory control

Table 2 Anastomotic leakage and course of treatment

\begin{tabular}{lll}
\hline Patient No & $\mathbf{3}$ & $\mathbf{4}$ \\
\hline Endo-SPONGE $^{\circledR}$ therapy (frequency) & 1 & $2 / 4$ \\
Length of treatment (days) & 3 & $5 / 12$ \\
Transanal suture & - & Yes \\
Reopening of ileostomy & - & Yes \\
Preserved anastomosis & Yes & Yes \\
Anastomotic leakage related mortality & - & - \\
\hline
\end{tabular}

confirmation via endoscopy), fistula, stenosis and pouch failure (Table 5).

\section{Data analysis}

Data analysis was performed using Microsoft Excel. Continuous variables were reported as mean or median values with range. Categorical variables were quantified using frequencies and percentage. Since the study population is too small to perform valid statistical testing, results are presented in a merely descriptive manner. Follow-up period started at the day of last operation. 
Table 3 Short-term pouch function (20-60 post operation)

\begin{tabular}{ll}
\hline Patients & $\mathbf{n = 1 4}$ \\
\hline Stool frequency $(\mathrm{n}=11)$ & \\
$2-5$ & 1 \\
$6-8$ & 3 \\
$9-10$ & 2 \\
$10-20$ & 5 \\
$>20$ & 0 \\
Incontinence & \\
None & 10 \\
Intermittent & 4 \\
Permanent & 0 \\
Pouchitis & 0 \\
Fistula & 0 \\
Stenosis & 0 \\
Pouch failure & 0 \\
\hline
\end{tabular}

\section{Results}

\section{Patient characteristics and operative details}

Gender distribution presented more male patients (male 14 patients; female 8 patients) with median age of $32 \pm 12.5(14-54)$ years at the time of taIPAA. The median time from first diagnosis of ulcerative colitis to subtotal colectomy was $36 \pm 104.5$ ( 1 - 408) months. Nineteen patients received a three-staged procedure as described earlier. Two patients were operated in a twostaged procedure with colectomy and pouch-formation in the same operation. Another patient did not receive diverting loop-ileostomy due to multiple adhesions in the second procedure. Detailed information on patients' demographics and clinical features as well as on the operation are shown in Table 1.

\section{Anastomotic leakage and postoperative clinical course} Complications according to Clavien-Dindo classification $>$ II took part over all three operation procedures, in total five patients. We observed one patient with severe complications for colectomy, three for pouch formation

Table 4 Long-term pouch function

\begin{tabular}{lllll}
\hline & $\mathbf{1 - 2}$ years & $\mathbf{2 - 3}$ years & $\mathbf{3 - 4}$ years & >4 years \\
\hline $\mathrm{n}$ & 11 & 12 & 5 & 6 \\
anastomotic leakage & 1 & 1 & 0 & 0 \\
Pouchitis & 5 & 5 & 2 & 0 \\
Fistula & 1 & 3 & 1 & 1 \\
Stenosis & 0 & 1 & 0 & 0 \\
Pouch failure & 1 & 1 & 1 & 0 \\
\hline
\end{tabular}

and three for ileostomy closure. After colectomy one patient developed a partial tear of terminal ileostomy which had to be addressed in the operating room. After pouch formation complications comprised gastrointestinal bleeding due to Mallory-Weiss lesions under therapeutic anticoagulation, high output stoma with acute kidney failure and consecutive temporary dialysis and early anastomotic leakage. After ileostomy reversal we saw two perforations located proximal to the ileo-ileal anastomosis and one anastomotic leakage of the ileo-ileal anastomosis.

Two patients of our cohort developed anastomotic leakage of ileal pouch-anal anastomosis. One patient was diagnosed with early anastomotic leakage on the 13th postoperative day. The second patient showed a late anastomotic leakage 19 months after diverting loop-ileostomy closure. Both patients were primarily treated with endosponge therapy and pouches could be preserved. The early anastomotic leakage required only one session of endosponge replacement, while late anastomotic leakage needed a multimodal approach including multiple endosponge changes.

The patient with late anastomotic leakage first received two cycles of endosponge therapy followed by a transanal suture completing the multimodal therapy procedure. Recurrence of anastomotic leakage 51 days after the aforementioned transanal suture was again treated with four cycles of endosponge therapy and reoperation for performing a diverting loop-ileostomy after the first cycle (Table 2). Definitive ileostomy closure could be achieved 380 days after last treatment for anastomotic leakage.

\section{Pouch function in the short- and long-term}

Clinical data of pouch function in the short-term was obtained for 14 patients (Table 3) with a median followup time of $39.5 \pm 9.2(29-59)$ days. None of the patients displayed any signs of pouchitis, fistula or stenosis. Pouch function was sufficient, as no permanent incontinence was observed. Intermittent incontinence, comprising stress induced incontinence and seepage due to liquid stool, was documented in four patients. Stool frequencies were reported for 11 patients, with one patient at a frequency of 2-5 times per day, three patients at 6-8 times per day and two patients at 9-10 times per day. Five patients recorded stool frequencies of 11-20 times per day.

In the long-term follow-up, comprising 1 to 5 years, 11 patients out of 19 patients developed pouchitis, at a mean of $475 \pm 327.3$ (91-1231) days after ileostomy closure (Table 5). Six patients were diagnosed within the first year after ileostomy closure. 
Table 5 Overview to pouchitis related characteristics

\begin{tabular}{|c|c|c|c|c|c|c|c|c|c|c|c|}
\hline Patient No & 1 & 5 & 6 & 8 & 11 & 12 & 13 & 14 & 16 & 18 & 20 \\
\hline Age & 34 & 39 & 30 & 41 & 35 & 48 & 33 & 33 & 17 & 36 & 59 \\
\hline $\mathrm{BMI}$ & 26.3 & 22.2 & 22 & 20.2 & 29.6 & 32.8 & 21.5 & 20.4 & 22.5 & 17 & 30.9 \\
\hline Cardiovascular disease & - & - & - & - & - & - & - & - & - & - & - \\
\hline Diabetes & - & - & - & - & - & - & - & - & - & - & - \\
\hline First diagnosed (days p.o.) & 586 & 1231 & 309 & 625 & 819 & 298 & 237 & 91 & 459 & 360 & 210 \\
\hline \multicolumn{12}{|l|}{ Extraintestinal manifestation } \\
\hline - Arthritis & Yes & - & - & - & - & Yes & - & - & - & - & - \\
\hline - Dermatitis & Yes & - & - & - & - & Yes & - & - & - & - & - \\
\hline - Primary sclerosing cholangitis & - & - & - & - & Yes & - & Yes & - & - & - & - \\
\hline - Other & - & - & - & - & - & - & - & $Y_{e s}^{a}$ & - & - & - \\
\hline Stenosis & - & - & - & - & - & - & - & - & - & - & Yes \\
\hline Fistula & Yes & - & - & - & - & Yes & - & - & - & - & Yes \\
\hline \multicolumn{12}{|l|}{ Treatment } \\
\hline - Antibiotics & Yes & Yes & Yes & Yes & Yes & Yes & - & Yes & - & - & - \\
\hline - Steroids (topical) & - & Yes & Yes & - & - & - & - & - & - & - & - \\
\hline - Steroids (systemic) & - & - & Yes & - & - & - & - & - & - & - & - \\
\hline - 5-aminosalicylic acid (topical) & - & Yes & Yes & - & - & Yes & - & - & - & Yes & - \\
\hline - Biologicals & - & - & Yes & - & - & Yes & Yes & - & Yes & - & - \\
\hline
\end{tabular}

${ }^{\mathrm{a}}$ idiopathic portal vein hypertension, BMI Body mass index

Additionally, three patients developed a fistula, all in direct coincidence to ileal-pouch-anal anastomosis. Out of those fistulas two were blind fistulas and one was a pouch-vaginal fistula with intermittent vaginal defecation.

The eight remaining patients had no endoscopic signs of pouchitis, while one presented a blind, asymptomatic fistula during routine postoperative endoscopy. One patient with pouchitis presented additional stenosis of the ileal pouch-anal anastomosis and was treated six times via ambulatory endoscopic dilatation. In 8 patients out of those 11 patients with pouchitis, a successful treatment was achieved with pharmacological therapy, comprising mainly antibiotics, topical and systemic steroids and in severe cases biologicals (Table 5). Meanwhile only 3 patients out of the pouchitis group still showed signs of pouchitis at last follow up. Here one patient was recommended for pouch removal and terminal ileostomy due to severe pouchitis with multiple fistulae. To date, the patient is in regular internal and surgical control and declines pouch removal.

\section{Discussion}

Transanal surgery has been studied mainly in transanal total mesorectal excision as therapy for rectal carcinoma and provides comparable oncological outcomes, yet better pathologic resection status, shorter operation time, lower conversion rate and lower overall postoperative complication rate in comparison to laparoscopic total mesorectal excision [12, 22-26]. Although the transanal approach for oncological surgery has been well researched since it was first performed for total mesorectal excision in 2010 [7] and offers improved surgical access to the otherwise often challenging, narrow pelvis [6], it is still not as widely established for benign indications such as ulcerative colitis. Currently, taIPAA is reported to provide comparable functional results and postoperative morbidity and mortality to the transabdominal approach with shorter operation time and conversion rate, but still study populations are relatively small and randomized controlled trials have not been conducted so far $[8,9,27]$.

In our study we observed complications r(ClavienDindo > II) in three patients for pouch formation, which is comparable to results reported recently for transabdominal IPAA [17] and even slightly lower than in two studies concerning taIPAA $[8,9]$. Nevertheless, these studies also showed higher complication rates for transabdominal IPAA resulting in no significant difference between both approaches. Anastomotic leakage occurred in two patients in our study. These results are consistent with findings for IPAA before implementation of the transanal approach $[18,28]$, and similar anastomotic leakage rates have also been shown for taIPAA [8, 9]. Chandrasinghe et al. even reported a trend for lower anastomotic leakage rates in taIPAA compared to transabdominal IPAA, 
which did not reach statistical significance [8] and could not be verified in our study. Course of treatment for anastomotic leakage after taIPAA has not yet been reported in detail.

In our study, only one early anastomotic leakage and one late anastomotic leakage was observed. Treatment was aimed at preserving the anastomosis and therefore founded on endosponge therapy. While early anastomotic leakages would be treated only with endosponge therapy, late anastomotic leakages required a multimodal approach consisting of endosponge therapy, transanal suture and reopening of the diverting loop-ileostomy. Our therapeutic approach relies on our experiences after transanal total mesorectal excision for rectal carcinoma, where we developed a differentiated therapy strategy for anastomotic leakage [20]. Endosponge therapy for anastomotic leakage after IPAA has not yet been widely researched, but the few studies existing show non-inferiority in comparison to conventional treatment and high rates of pouch preservation [21,29].

In our study, we did not observe any pouch failure due to anastomotic leakage with an overall pouch failure in one patient, which is also consistent with earlier findings $[8,17]$. The only detected patient with pouch failure had an underlying severe pouchitis which was therapy refractory to pharmalogical treatment and therefore recommended for pouch removal and terminal ileostomy.

Pouchitis is one of the most frequent complications after IPAA $[28,30]$ and associated with significant morbidity and reduced quality of life [31,32]. Pouchitis rates after IPAA reach up to $60 \%$ with increasing incidence during postoperative follow-up [16, 30, 33] and may result in chronic pouch dysfunction and in severe cases pouch failure [34]. The overall pouchitis rate was 11 patients, with half of the patients developing symptoms within one year after the last operation. Furthermore, pharmacological treatment was successful in 8 patients resulting in a good functional outcome in long-term follow-up. There are still only few studies on treatment for acute and chronic pouchitis leaving therapeutic strategies with highly variable outcomes and lacking sufficient scientific evidence $[35,36]$.

In order to improve therapy for pouchitis more research is needed. In the only study comparing longterm results of taIPAA and transabdominal IPAA, no significant difference was found neither between pouchitis rates nor health related quality of life including sexual function [8]. Long-term follow-up for transabdominal IPAA shows over $90 \%$ of patients being satisfied with the operative result, despite minor complications such as nocturnal seepage or higher daily stool frequencies $[17,37,38]$.
Our study is limited by its retrospective design without option to rule out potential bias, especially selection bias. The restricted number of patients does not suffice for statistical evaluation of our results. However, the monocentric design of our study ensures that the same experienced colorectal surgeons' team performed all procedures, resulting in excellent comparability of postoperative outcomes.

\section{Conclusion}

In our study, anastomotic leakage rates, postoperative complications as well as short- and long-term outcome of taIPAA were comparable to previously published results for only tranabdominal surgery. Still, postoperative complications remain an area of concern in colorectal surgery for benign colorectal disease, especially ulcerative colitis. Since taIPAA was introduced only a few years ago, studies for long-term outcomes and evaluation of larger patient cohorts are necessary to fully understand possible advantages or downsides of this surgical approach.

\section{Abbreviations}

ASA: American society of Anaesthesiologists; BMI: Body mass index; IBD: Inflammatory bowel disease; talPAA: Transanal ileal pouch-anal anastomosis.

\section{Authors' contributions}

AL collected the data and wrote the paper. FA and MB performed the surgery and supervised and corrected the manuscript. LD collected the data. AF and AA helped with data acquisition. FT supervised conservative patient treatment and corrected the manuscript. RS, SC, MK and JP supervised the study and corrected the manuscript. SGK designed and performed the study, wrote and corrected the paper. All authors have made substantial contributions to the study, including conception and design, the acquisition, analysis and interpretation of data, drafting or critical revision of the paper. All authors read and approved the final manuscript.

\section{Funding}

Open Access funding enabled and organized by Projekt DEAL. We acknowledge support from the German Research Foundation (DFG) and the Open Access Publication Fund of Charité - Universitätsmedizin Berlin.

\section{Availability of data and materials}

The datasets used and/or analyzed during the current study are available from the corresponding author on reasonable request.

\section{Declarations}

Ethics approval and consent to participate

An authorization for this study has been granted by the Charité Ethics Committee (Reg. No. 711/16).

\section{Consent for publication \\ All patients gave written informed consent for the international LOREC ${ }^{\circledR}$ registry.}

\section{Competing interests}

The authors declare that they have no competing interests.

\section{Author details}

${ }^{1}$ Department of Surgery, Campus Charité Mitte and Campus VirchowKlinikum, Charité - Universitätsmedizin Berlin, Augustenburger Platz 1, 13353 Berlin, Germany. ${ }^{2}$ Department of Hepatology and Gastroenterology, Charité - Universitätsmedizin Berlin, Freie Universität Berlin and Humboldt 
Universität zu Berlin, Berlin, Germany. ${ }^{3}$ Department of Surgery, Barmherzige Brüder Krankenhaus Graz, Graz, Austria.

Received: 29 June 2021 Accepted: 23 August 2021 Published online: 18 September 2021

\section{References}

1. Ng SC, Shi HY, Hamidi N, Underwood FE, Tang W, Benchimol El, et al. Worldwide incidence and prevalence of inflammatory bowel disease in the 21st century: a systematic review of population-based studies. Lancet. 2018;390(10114):2769-78. https://doi.org/10.1016/S0140-6736(17) 32448-0.

2. Kornbluth A, Sachar DB, Practice Parameters Committee of the American College of G. Ulcerative colitis practice guidelines in adults: American College Of Gastroenterology, Practice Parameters Committee. Am J Gastroenterol. 2010;105(3):501-23. https://doi.org/10.1038/ajg.2009.727 quiz 24.

3. Targownik LE, Singh H, Nugent Z, Bernstein CN. The epidemiology of colectomy in ulcerative colitis: results from a population-based cohort. Am J Gastroenterol. 2012;107(8):1228-35. https://doi.org/10.1038/ajg. 2012.127.

4. Fleming FJ, Francone TD, Kim MJ, Gunzler D, Messing S, Monson JR. A laparoscopic approach does reduce short-term complications in patients undergoing ileal pouch-anal anastomosis. Dis Colon Rectum. 2011;54(2):176-82. https://doi.org/10.1007/DCR.0b013e3181fb4232.

5. Wu XJ, He XS, Zhou XY, Ke J, Lan P. The role of laparoscopic surgery for ulcerative colitis: systematic review with meta-analysis. Int J Colorectal Dis. 2010;25(8):949-57. https://doi.org/10.1007/s00384-010-0898-5.

6. Atallah S, Martin-Perez B, Albert M, deBeche-Adams T, Nassif G, Hunter $L$, et al. Transanal minimally invasive surgery for total mesorectal excision (TAMIS-TME): results and experience with the first 20 patients undergoing curative-intent rectal cancer surgery at a single institution. Tech Coloproctol. 2014;18(5):473-80. https://doi.org/10.1007/ s10151-013-1095-7.

7. Sylla P, Rattner DW, Delgado S, Lacy AM. NOTES transanal rectal cancer resection using transanal endoscopic microsurgery and laparoscopic assistance. Surg Endosc. 2010;24(5):1205-10. https://doi.org/10.1007/ s00464-010-0965-6.

8. Chandrasinghe P, Carvello M, Wasmann K, Foppa C, Tanis P, PerryWoodford Z, et al. Transanal ileal pouch-anal anastomosis for ulcerative colitis has comparable long-term functional outcomes to transabdominal approach: a multicentre comparative study. J Crohns Colitis. 2020;14(6):726-33. https://doi.org/10.1093/ecco-jcc/ jjz174.

9. de Buck van Overstraeten A, Mark-Christensen A, Wasmann KA, Bastiaenen VP, Buskens CJ, Wolthuis AM, et al. Transanal versus transabdominal minimally invasive (completion) proctectomy with ileal pouch-anal anastomosis in ulcerative colitis: a comparative study. Ann Surg. 2017;266(5):878-83. https://doi.org/10.1097/SLA.0000000000002395.

10. Capolupo GT, Carannante F, Masciana G, Lauricella S, Mazzotta E, Caricato M. Transanal proctocolectomy and ileal pouch-anal anastomosis (TaIPAA) for ulcerative colitis: medium term functional outcomes in a single centre. BMC Surg. 2021;21(1):17. https://doi.org/10.1186/ s12893-020-01007-z.

11. Boccola MA, Buettner PG, Rozen WM, Siu SK, Stevenson AR, Stitz R, et al. Risk factors and outcomes for anastomotic leakage in colorectal surgery: a single-institution analysis of 1576 patients. World J Surg. 2011;35(1):186-95. https://doi.org/10.1007/s00268-010-0831-7.

12. Penna M, Hompes R, Arnold S, Wynn G, Austin R, Warusavitarne J, et al. Incidence and risk factors for anastomotic failure in 1594 patients treated by transanal total mesorectal excision: results from the international TaTME registry. Ann Surg. 2019;269(4):700-11. https://doi.org/10. 1097/SLA.0000000000002653.

13. Nesbakken A, Nygaard K, Lunde OC. Outcome and late functional results after anastomotic leakage following mesorectal excision for rectal cancer. Br J Surg. 2001;88(3):400-4. https://doi.org/10.1046/j. 1365-2168.2001.01719.x.
14. Mirnezami A, Mirnezami R, Chandrakumaran K, Sasapu K, Sagar P, Finan $P$. Increased local recurrence and reduced survival from colorectal cancer following anastomotic leak: systematic review and meta-analysis. Ann Surg. 2011;253(5):890-9. https://doi.org/10.1097/SLA.0b013e3182 128929.

15. Khoury W, Lavery IC, Kiran RP. Impact of early reoperation after resection for colorectal cancer on long-term oncological outcomes. Colorectal Dis. 2012;14(3):e117-23. https://doi.org/10.1111/j.1463-1318. 2011.02804.x.

16. Barnes EL, Herfarth HH, Kappelman MD, Zhang X, Lightner A, Long MD, et al. Incidence, risk factors, and outcomes of pouchitis and pouchrelated complications in patients with ulcerative colitis. Clin Gastroenterol Hepatol. 2020. https://doi.org/10.1016/j.cgh.2020.06.035.

17. Carcamo L, Miranda P, Zuniga A, Alexander E, Molina ME, Urrejola G, et al. Ileal pouch-anal anastomosis in ulcerative colitis: outcomes, functional results, and quality of life in patients with more than 10-year follow-up. Int J Colorectal Dis. 2020;35(4):747-53. https://doi.org/10. 1007/s00384-020-03529-7.

18. Sahami S, Bartels SA, D'Hoore A, Fadok TY, Tanis PJ, Lindeboom R, et al. A multicentre evaluation of risk factors for anastomotic leakage after restorative proctocolectomy with ileal pouch-anal anastomosis for inflammatory bowel disease. J Crohns Colitis. 2016;10(7):773-8. https:// doi.org/10.1093/ecco-jcc/jjv170.

19. Boyce SA, Harris C, Stevenson A, Lumley J, Clark D. Management of low colorectal anastomotic leakage in the laparoscopic era: more than a decade of experience. Dis Colon Rectum. 2017;60(8):807-14. https:// doi.org/10.1097/DCR.0000000000000822.

20. Guel-Klein S, Biebl M, Knoll B, Dittrich L, Weiss S, Pratschke J, et al. Anastomotic leak after transanal total mesorectal excision: grading of severity and management aimed at preservation of the anastomosis. Colorectal Dis. 2019;21(8):894-902. https://doi.org/10.1111/codi. 14635.

21. Wasmann KA, Reijntjes MA, Stellingwerf ME, Ponsioen CY, Buskens CJ, Hompes R, et al. Endo-sponge Assisted Early Surgical Closure of ileal pouch-anal anastomotic leakage preserves long-term function: a cohort study. J Crohns Colitis. 2019;13(12):1537-45. https://doi.org/10. 1093/ecco-jcc/jjz093.

22. Ma B, Gao P, Song Y, Zhang C, Zhang C, Wang L, et al. Transanal total mesorectal excision (taTME) for rectal cancer: a systematic review and meta-analysis of oncological and perioperative outcomes compared with laparoscopic total mesorectal excision. BMC Cancer. 2016;16:380. https://doi.org/10.1186/s12885-016-2428-5.

23. Chang TC, Kiu KT. Transanal total mesorectal excision in lower rectal cancer: comparison of short-term outcomes with conventional laparoscopic total mesorectal excision. J Laparoendosc Adv Surg Tech A. 2018;28(4):365-9. https://doi.org/10.1089/lap.2017.0520.

24. Burke JP, Martin-Perez B, Khan A, Nassif G, de Beche-Adams T, Larach SW, et al. Transanal total mesorectal excision for rectal cancer: early outcomes in 50 consecutive patients. Colorectal Dis. 2016;18(6):570-7. https://doi.org/10.1111/codi.13263.

25. Lacy AM, Tasende MM, Delgado S, Fernandez-Hevia M, Jimenez M, De Lacy B, et al. Transanal total mesorectal excision for rectal cancer: outcomes after 140 patients. J Am Coll Surg. 2015;221(2):415-23. https:// doi.org/10.1016/j.jamcollsurg.2015.03.046.

26. Dittrich L, Biebl M, Schmuck R, Gul S, Weiss S, Haase O, et al. Initial experience with the safe implementation of transanal total mesorectal excision (TaTME) as a standardized procedure for low rectal cancer. J Clin Med. 2020;10(1) DOI: https://doi.org/10.3390/jcm10010072.

27. de Lacy FB, Keller DS, Martin-Perez B, Emile SH, Chand M, Spinelli A, et al. The current state of the transanal approach to the ileal pouchanal anastomosis. Surg Endosc. 2019;33(5):1368-75. https://doi.org/10. 1007/s00464-019-06674-5.

28. Hueting WE, Buskens E, van der Tweel I, Gooszen HG, van Laarhoven CJ. Results and complications after ileal pouch anal anastomosis: a meta-analysis of 43 observational studies comprising 9,317 patients. Dig Surg. 2005;22(1-2):69-79. https://doi.org/10.1159/000085356.

29. Rottoli M, Di Simone MP, Vallicelli C, Vittori L, Liguori G, Boschi L, et al. Endoluminal vacuum-assisted therapy as treatment for anastomotic leak after ileal pouch-anal anastomosis: a pilot study. Tech Coloproctol. 2018;22(3):223-9. https://doi.org/10.1007/s10151-018-1762-9. 
30. Simchuk EJ, Thirlby RC. Risk factors and true incidence of pouchitis in patients after ileal pouch-anal anastomoses. World J Surg. 2000;24(7):851-6. https://doi.org/10.1007/s002680010136.

31. Turina M, Pennington CJ, Kimberling J, Stromberg AJ, Petras RE, Galandiuk S. Chronic pouchitis after ileal pouch-anal anastomosis for ulcerative colitis: effect on quality of life. J Gastrointest Surg. 2006;10(4):6006. https://doi.org/10.1016/j.gassur.2005.08.013.

32. Barnes EL, Herfarth HH, Sandler RS, Chen W, Jaeger E, Nguyen VM, et al. Pouch-related symptoms and quality of life in patients with ileal pouch-anal anastomosis. Inflamm Bowel Dis. 2017;23(7):1218-24. https://doi.org/10.1097/MIB.0000000000001119.

33. Peyrin-Biroulet L, Germain A, Patel AS, Lindsay JO. Systematic review: outcomes and post-operative complications following colectomy for ulcerative colitis. Aliment Pharmacol Ther. 2016;44(8):807-16. https:// doi.org/10.1111/apt.13763.

34. Fazio VW, Kiran RP, Remzi FH, Coffey JC, Heneghan HM, Kirat HT, et al. Ileal pouch anal anastomosis: analysis of outcome and quality of life in 3707 patients. Ann Surg. 2013;257(4):679-85. https://doi.org/10.1097/ SLA.0b013e31827d99a2.

35. Nguyen N, Zhang B, Holubar SD, Pardi DS, Singh S. Treatment and prevention of pouchitis after ileal pouch-anal anastomosis for chronic ulcerative colitis. Cochrane Database Syst Rev. 2019;11:CD001176. https://doi.org/10.1002/14651858.CD001176.pub5.

36. Suzuki H, Ogawa H, Shibata C, Haneda S, Watanabe K, Takahashi K, et al The long-term clinical course of pouchitis after total proctocolectomy and IPAA for ulcerative colitis. Dis Colon Rectum. 2012;55(3):330-6. https://doi.org/10.1097/DCR.0b013e3182417358.

37. Hahnloser D, Pemberton JH, Wolff BG, Larson DR, Crownhart BS, Dozois RR. Results at up to 20 years after ileal pouch-anal anastomosis for chronic ulcerative colitis. Br J Surg. 2007;94(3):333-40. https://doi.org/ 10.1002/bjs.5464

38. McIntyre PB, Pemberton JH, Wolff BG, Beart RW, Dozois RR. Comparing functional results one year and ten years after ileal pouch-anal anastomosis for chronic ulcerative colitis. Dis Colon Rectum. 1994;37(4):303-7. https://doi.org/10.1007/BF02053588.

\section{Publisher's Note}

Springer Nature remains neutral with regard to jurisdictional claims in published maps and institutional affiliations.
Ready to submit your research? Choose BMC and benefit from:

- fast, convenient online submission

- thorough peer review by experienced researchers in your field

- rapid publication on acceptance

- support for research data, including large and complex data types

- gold Open Access which fosters wider collaboration and increased citations

- maximum visibility for your research: over $100 \mathrm{M}$ website views per year

At BMC, research is always in progress.

Learn more biomedcentral.com/submissions 